\title{
Pengaruh Tradisi Sekatenan Terhadap Perilaku Keagamaan Masyarakat Yogyakarta
}

\author{
Melati Indah Al-Fajriyati* \\ UIN Sunan Gunung Djati Bandung, Indonesia \\ Email: indahmm@gmail.com
}

\begin{abstract}
In every major religion in Indonesia, it is also known by the celebration of certain religious holidays, call it Islam. In the Islamic religion there are also known as Islamic Festivals namely Eid al-Fitr and Eid al-Adha, there are also commemorating the birthday of the Prophet Muhammad, who in some traditions vary in their mention and procedure. As in the Special Region of Yogyakarta, referred to as the Sekatenan Tradition. This article looks at the Sekatenan Tradition as part of the rite activities of the Yogyakarta Palace and its people. The different patterns of interaction and behavior of the people of Yogyakarta continue to accumulate by the time this tradition can lead to life in the community. These traditions provide a special trust that grows in the community. Transcendental Javanese native culture is more inclined to understand animism and dynamism. The method used in this study is a qualitative approach with descriptive analytic methods. Resulting in the existence of Islamic values contained in the Sekatenan Tradition in the form of symbols. The religious religiosity content of the Keraton community along with the entry of Islam into Java is a form of the philosophy of "mikul dhuwur medem jero" (is a description of how Islam embraces all strata of society, from nobles to ordinary people. Touching every aspect of life, withdraw and regulate it with the laws and norms that Islam teaches but not to leave the existing culture of the palace against the struggle of Wali Songo who has succeeded in spreading the demands of the Prophet Muhammad.
\end{abstract}

Keywords: sekatenan; Yogyakarta; Islam.

\begin{abstract}
Abstrak
Dalam setiap agama-agama besar di Indonesia dikenal juga dengan adanya perayaan hari-hari besar keagamaan tertentu, sebut saja Islam. Dalam agama Islam dikenal juga ada Hari Raya Umat Islam yaitu Idul Fitri dan Idul Adha, ada juga memperingati hari kelahiran Nabi Muhammad SAW., yang dalam beberapa tradisi masyarakat berbeda-beda penyebutan dan tata caranya. Seperti di daerah Istimewa Yogyakarta, disebut dengan istilah Tradisi Sekatenan. Artikel ini melihat Tradisi Sekatenan sebagai bagain dari kegiatan ritus dari Keraton Yogyakarta dan masyarakatnya. Perbedaan pola interaksi dan tingkah laku masyarakat Yogyakarta ini terus berakumulasi oleh waktu yang membawa tradisi ini bisa sampai hidup di masyarakat. Tradisi-tradisi ini memberikan kepercayaan tersendiri yang tumbuh di masyarakat. Kebudayaan asli Jawa yang bersifat transendental lebih cenderung pada paham animisme dan dinamisme. Metode yang digunakan dalam penelitian ini adalah pendekatan kualitatif dengan metode deskriptif analitik. Menghasilkan adanya nilai-nilai Islam yang terkandung dalam Tradisi Sekatenan yang berbentuk simbol-simbol. Muatan-muatan religiusitas ke-Islaman masyarakat Keraton seiring dengan masuknya agama Islam ke Jawa adalah merupakan wujud dari falsafah "mikul dhuwur medem jero" (adalah gambaran, bagaimana Islam merangkul seluruh lapisan masyarakat, dari kalangan ningrat sampai masyarakat jelata. Menyentuh setiap aspek kehidupan, menarik dan mengaturnya dengan hukum dan norma-norma yang Islam ajarkan tapi tidak sampai meningglkan budaya yang sudah ada--pen) dari keraton terhadap perjuangan Wali Songo yang telah berhasil menyebarkan tuntutan Nabi Muhammad SAW.
\end{abstract}

Kata Kunci: sekatenan; Yogyakarta; Islam.

\section{PENDAHULUAN}

Indonesia sebagai bangsa timur mengenal etika sebagai prinsip-prinsip dasar pergaulan antar individu, maupun kelompok dengan individu, baik buruknya etika bergantung pada sistem nilai yang

* Corresponding author

Received: September 01, 2019; Revised: October 19, 2019; Accepted: December 26, 2019 
mempengaruhi seperti budaya, agama, dan lain-lain. Dalam setiap agama-agama besar di Indonesia dikenal juga dengan adanya perayaan hari-hari besar keagamaan tertentu, sebut saja Islam. Dalam agama Islam dikenal juga ada Hari Raya Umat Islam yaitu Idul Fitri dan Idul Adha, ada juga memperingati hari kelahiran Nabi Muhammad SAW (Simuh, 2008)., yang dalam beberapa tradisi masyarakat berbeda-beda penyebutan dan tata caranya. Seperti di daerah Istimewa Yogyakarta, disebut dengan istilah Tradisi Sekatenan.

Tradisi Sekatenan adalah salah satu istilah yang digunakan masyarakat Jawa dalam memperingati hari lahir Nabi Muhammad atau disebut juga dengan istilah Maulid Nabi,. Acara Sekaten yang diadakan untuk memperingati Maulid Nabi Muhammad SAW diakhiri dengan acara Grebeg Maulud. Grebeg adalah upacara adat berupa sedekah yang dilakukan pihak keraton kepada masyarakat berupa gunungan (Purwadi, 2005).

Daerah Istimewa Yogyakarta mengalami perubahan yang cukup signifikan di bidang kehidupan sosial, akan tetapi tidak mengalami perubahan yang banyak di bidang kebudayaan karena masyarakat Yogyakarta memegang teguh nilai-nilai yang sudah ada sejak dulu. Daerah Istimewa Yogyakarta mempunyai prospek yang cukup tinggi terhadap permintaan pasar wisatawan karena memiliki keindahan panorama alam, iklim dan keanekaragaman hayati yang merupakan daya tarik tersendiri, terutama unsur kebudayaan Yogyakarta yang kental sekali baik di masyarakatnya dan juga dari pihak keratonnya sendiri (Soelarto, 1993). Selain itu kebudayaan atau tradisi-tradisi masyarakatnya pun merupakan sebuah daya tarik tersendiri yang bisa menarik para pengunjung dari luar Indonesia dan itu merupakan pontensi yang ada di Daerah Istimewa Yogyakarta. Disamping itu Keraton merupakan kawasan sentral masyarakat dalam melakukan aktivitas, letaknya yang cukup strategis karena berada di alun-alun Malioboro yang berfungsi sebagai Jantung kota ini. Dengan keunikan kebudayaan ataupun keberagamaannya, Daerah Istimewa Yogyakarta adalah dianggap sebagai salah satu tempat yang tepat untuk dijadikan tempat penelitian. Tradisi Sekatenan adalah salah satu bentuk dari warisan budaya yang dilestarikan hingga sekarang, tradisi ini sering diselenggarakan ketika memperingati Maulid (hari lahirnya) Nabi Muhammad SAW., dan di dalamnya ada ritual mencuci benda-benda pusaka Keraton Yogyakarta.

Dalam realitanya, tidak ada yang berbeda antara kebudayan masyakat Yogyakarta dengan yang lainnya dalam memperingati Maulid Nabi, tetapi yang menjadi unik di tradisi Sekatenan ini yaitu adanya Gunungan yang diarak ketika puncak acara Sekatenan dan sering dijadikan bahan rebutan masyarakat yang mengikuti proses upacara adat ini.

Fenomena ini menarik untuk diteliti, terutama dari aspek sinkritisisme (ritus keagamaan), dan budaya lokal masyarakat Yogyakarta (Brongtodiningrat, 1982). Dan menelusuri lebih dalam lagi, bagaimana fakta sosial atau kondisi objektif, baik itu secara struktural fungsional yang berkaitan dengan kehidupan masyarakat secara umum, atau kehidupan tradisi masyarakat (Astiyanto, 2006), dan kehidupan keberagamaannya serta unsur-unsur keislaman dalam tradisi Sekaten ini. Dan jika dikelompokkan menjadi beberapa sub, antara lain: sub-sistem budaya, sub-sistem sosial, sub-sistem kepribadian masyarakat dan sub-sistem organik (Sultan dan keluarganya). Untuk dapat menindaklanjuti fenomena-fenomena yang akan terjadi dalam sebuah kesatuan kultur budaya masyarakat Yogyakarta.

\section{METODE PENELITIAN}

Penelitian ini merupakan jenis penelitian kualitatif dengan metode deskriptif analitik dan teknik pengumpulan data menggunakan observasi, wawancara, dan dokumentasi (Sugiyono, 2013). Data penelitian yang terkumpul kemudian dianalisis dengan langkah mengumpulkan data yang diperlukan, 
mengklasifikasikan data menjadi data primer dan data skunder. Data-data yang bersifat kata-kata atau kalimat digunakan analisis kualitatif yaitu dengan cara memberikan interpretasi sesuai dengan maksud yang terkandung dalam kata-kata atau kalimat tersebut. Menelaah seluruh data yang tersedia dari berbagai sumber melalui observasi dan wawancara dengan cara dipelajari, ditelaah yang selanjutnya dipahami. Dan selanjutnya peneliti berusaha menyimpulkan data tersebut, sehingga diharapkan penelitian menuju pokok permasalahan yaitu sebagaimana yang tertera dalam kerangka pemikiran dan latar belakang masalah yaitu untuk menjawab pertanyaan-pertanyaan penelitian (Cresswell John W, 2014).

\section{HASIL DAN PEMBAHASAN}

\section{Pengaruh Tradisi Sekatenan terhadap Perilaku Keagamaan Masyarakat Yogyakarta}

Sunan Kalijaga adalah seorang Wali yang sangat inovatif. Dia memang Inovator di zamannya. Sunan banyak berkreasi dalam kehidupan masyarakat. Sunan tidak mau menjiplak begitu saja apa yang berasal dari luar Nusantara. Sunan diangkat menjadi anggota Wali Sanga, tetapi Sunan tidak mau menggunakan baju gamis dan bersorban [beserban] ala ulama-ulama yang berasal dari Timur Tengah. Sunan justru merancang baju yang sesuai dengan keadaan iklim dan cuaca di Nusantara. Sunan menciptakan baju yang disebut "baju takwa" . Surjan Jawa yang semula lengan baju pendek, diganti dengan lengan panjang. Di ujung lengan tanpa diberi belahan. Jadi terasa longgar jika dipakai. Cocok bagi orang Jawa yang cuacanya mudah sekali membuat orang berkeringat. Dengan baju takwa di tubuh terasa sejuk. Itulah inovasi Sunan. Sunan juga tidak mengenakan serban yang digunakan sebagai tutup kelapanya adalah "blangkon", yaitu ikat kepala yang sudah jadi, tinggal dipakai. Blangkon ini masih banyak digunakan di daerah Solo dan Yogyakarrta. Dalang dan penabuh gamelan wayang kulit pun menggunakan blangkon.(Chodjim, 2006)

Sebelum Islam masuk Jawa, wayang purwa-biasanya dalam bentuk kulit-telah digunakan untuk mendidik budi pekerti dan moralitas orang Jawa. Sunan Klaijaga juga memanfaatkan wayang untuk dakwah agama Islam. Banyak unsur Islam yang dimasukkan ke dalam wayang. Pusaka ini ada tulisan dan setelah dibaca ternyata "kalimat syahadat". Ya, rukun pertama dalam agama Islam ialah membaca kalimat syahadat. Dia tidak membongkar kebudayaan yang ada, tetapi mengisinya untuk keperluan dakwah Islam. Sungguh Sunan telah berinovasi dalam dakwah. Selain di bidang seni musik [gamelan] dan seni lukis, Sunan Kalijaga juga berinovasi dalam bidang pertanian. Gerebeg Mulud dan Sekaten. Dua institusi spiritual yang dimanfaatkan Sunan untuk melakukan dakwah dengan pendekatan budaya (Beratha, 1982).

Sekaten adalah perayaan hari lahir Nabi Muhammad SAW, tradisi Keraton Mataram. Ini nuansa budaya Jawa, ini berasal dari Demak, kerajaan Islam pertama Demakbintoro. Rakyat ini kemudian diajak masuk Islam, dengan cara arif dan bijaksana, bukan dengan model kekerasan, damai dan sejuk. Para wali mencari cara mengumpulkan rakyat, kemudian ada gamelan dari jaman Majapahit, namanya Kyai Sekati. Ditabuhlah gamelan, orang-orang mendengar, dulu itu masing langkanya hiburan. Rakyat berbondong-bondong sambil meneginang (perempuan dan laki-laki), yang pria bersorjan, bercelana panting, ubed-ubed jarit dan belum bersandal. Yang wanita berpakaian kurung (baju Lurik), menginang, gelung pakai tusuk konde. Setelah rampung gamelan, lalu diteragkan oleh para Wali itu apa, bagaimana, siapa Nabi Muhammad saw itu. Apa dan bagaimana Islam itu, padahal mereka kan masih beragama Hindu sehingga asing itu mendengar keterangan itu, reaksinya orang macam-macam, ada yang pro, ada yang kontra, ada yang masih setengah-setengah, kalau yang oke, yang setuju masuk Islam, caranya membaca 
dua kalimat syahadat. Dari tahun ke tahun, cara itu lalu terkenal dengan Syahadatain, lalu muncullah istilah Sekaten sampai sekarang.

Sekaten seminggu, lalu ditutup pada hari H-nya raja mengeluarkan sedekah, sedekah ratu atau raja dikonsep berupa Gunungan, gunungan itu lalu sedekahnya Raja untuk rakyat. Sebelum dibagi itu di doakan, lalu dibagi, kalau dulu itu begitu, karena rakyatnya masih sedikit dan masih manut. Tapi kenyataan yang ada di lapangan, ketika Gunungan datang, baru mau memasuki Masjid saja masyarakat langsung menggarebeg Gunungan tersebut, padahal secara adat itu harus di doakan terlebih dahulu, baru kemudian dibagikan pada khalayak ramai.

Seperti yang telah dikemukan di atas, kalau kita melihat aspek pengaruh keberagamaan dari tradisi Sekatenan ini, dari hasil wawancarapun didapatkan data, bahwa itu semua dikembalikan kembali pada individu-individu secara personal. Sultan tidak memaksakan atau pun memerintahkan untuk berebut gunungan untuk di anggap sebagai berkah. Bahkan sultan secara pribadi melarang untuk merebutkannya, karena takut akan menimbulkan hal-hal yang dianggap melenceng dari ajaran agama.

Akan tetapi, jika kita membalikkannya pada masyarakat Yogyakarta yang percaya dan mengikuti setiap ritual di keraon Yoyakarta, itu akan berbeda (G.Moedjanto, 1987). Karena menurut pemahaman mereka yang diwariskan dari keturunan terdahulu mereka, mereka percaya segala sesuatu yang dikeluarkan keraton adalah berkah tersendiri bagi mereka. Itu adalah sesuatu yang sangat berharga nilainya bagi dirinya sendiri ataupun keluarga.

Bagi sebagian masyarakat yang lain yang benar-benar Islam, mereka mengikuti tradisi ini dari sisi keberagamaannya. Yaitu dengan mengikuti pengajian-pengajian yang diadakan disela-sela bunyi-bunyian gamelan yang diadakan di Masjid Gedhe Kauman. Mengikuti doa bersama, tidak sematamata ngalap berkah seperti masyarakat yang lain, akan tetapi juga mengharapkan keselamatan dunia dan akhirat dan lain sebagainya. Terutama terhindar dari segala mara bahaya yang sekarang-sekarang ini sering mengancam daerah Istimewa Yogyakarta yaitu Bencana Alam, baik itu gunung meletus atau Tsunami.

Perayaan Sekatenan yang dilaksanakan setahun sekali selama tujuh hari menjelang peringatan Maulud Nabi Muhammad SAW., dan dimulai sejak abad XV hingga abad XX yaitu sejak zaman Sunan Kalijaga di dua keraton bekas Kerajaan Mataram yaitu keraton Yogyakarta dan keraton Surakarta. Seiring dengan masuknya agama Islam ke Jawa adalah merupakan wujud dari falsafah "mikul dhuwur medem jero" dari keraton terhadap perjuangan Wali Songo yang telah berhasil menyebarkan tuntutan Nabi Muhammad SAW. Sekaten sendiri berasal dari kata Syahadatain yang substansinya adalah mengenalkan dua kalimat Syahadat untuk memperkenalkan ajaran tauhid dan sekaligus tidak mengorbankan apalagi melupakan budaya Jawa. Sedangkan proses ritualnya yaitu dimulai dengan dikeluarkannya dua gamelan dari tempat penyimpanannya di Bangsal Sri Manganti yakni Kyai Guntur Madu dan Kyai Naga Wilaga lalu disinggahkan ke Bangsal Ponconiti yang kemudian dengan pengawal para prajurit keraton dibawa ke halaman Masjid Agung Gedhe Kauman dan diakhiri dengan gerebeg Gunungan Sekaten (Djojowadono, 1989).

Simbol sinkretisme politik Jawa-Islam tampak menyolok pada gelar raja-raja Jawa Islam seperti gelar Sultan, kalifahtullah sayyidin panatagama, tetunggul khalifatul Mu'minin, susuhunan, dan sebagainya. Simbol sinkretisme politik Islam-Jawa juga tredapat pada raja-raja Yogyakarta yang dipegang Sri sultan Hamengkubuwono.

Untuk pemahaman masyarakat tentang makna dan simbol Sekatenan ini, ternyata masyarakat kurang banyak memahami dan mengetahui apa makna dan simbol dari sekaten. Mereka hanya mengetahui hal-hal yang hanya bersifat umum, kalau Sekaten adalah hanya sebuah bentuk dari 
perwujudan kebudayaan yang harus dilestarikan, Sekaten adalah warisan budaya dari para wali, yaitu Sunan Kalijaga. Jadi kebanyakan masyarakat Yogyakartanya sendiri hanya sebagian kecil saja yang masih mengikuti ritualnya, hanya pas upacara ritual Gerebegnya saja, karena untuk ngalap berkah saja menurut kepercayaan mereka. Kalaupun ada yang paham dan tau, mungkin pada zaman sekarang ini hanya beberapa orang saja. Kalaupun mereka mengikuti upacara tradisi Sekaten ini, hanya karena berpartisipasi dalam menjaga kelestarian budaya (Herusatoto, 2001). Tidak semata-mata faham betul.

\section{SIMPULAN}

Perayaan Sekatenan yang dilaksanakan setahun sekali selama tujuh hari menjelang peringatan Maulud Nabi Muhammad SAW., dan dimulai sejak abad XV hingga abad XX yaitu sejak zaman Sunan Kalijaga di dua keraton bekas Kerajaan Mataram yaitu keraton Yogyakarta dan keraton Surakarta. Seiring dengan masuknya agama Islam ke Jawa adalah merupakan wujud dari falsafah "mikul dhuwur medem jero" (gambaran bagaimana Islam merangkul seluruh lapisan masyarakat dari kalangan ningrat sampai masyarakat jelata. Menyentuh setiap aspek kehidupan, menarik dan mengaturnya dengan hukum dan norma-norma yang Islam ajarkan tapi tidak sampai meningglkan budaya yang sudah ada-pen) dari keraton terhadap perjuangan Wali Songo yang telah berhasil menyebarkan tuntutan Nabi Muhammad SAW. Sekaten sendiri berasal dari kata Syahadatain yang substansinya adalah mengenalkan dua kalimat Syahadat untuk memperkenalkan ajaran tauhid dan sekaligus tidak mengorbankan apalagi melupakan budaya Jawa. Sedangkan proses ritualnya yaitu dimulai dengan dikeluarkannya dua gamelan dari tempat penyimpanannya di Bangsal Sri Manganti yakni Kyai Guntur Madu dan Kyai Naga Wilaga lalu disinggahkan ke Bangsal Ponconiti yang kemudian dengan pengawal para prajurit keraton dibawa ke halaman Masjid Agung Gedhe Kauman dan diakhiri dengan gerebeg Gunungan Sekaten. Nilai-nilai budaya dan nilai-nilai relegius yang terkandung dalam perayaan Sekatenan di antaranya adalah pada saat tradisi berlangsung dari pagi sampai malam di Bangsal Pagongan Masjid Gedhe Kauman Keraton dibunyikan dua perangkakat gamelan. Yang dapat disimak adalah dari gending-gending tersebut adalah makna keagamaannya. Gending pertama adalah gending Rambu yang diolah oleh para wali atas puji syukur yang berasal dari Rabbulngalamin yang berarti Tuhan yang menguasai seluruh alam. Dan gamelan yang ditabuh dengan jarak agak lama merupakan simbol dari kesabaran para wali dalam menyebarkan ajaran Islam. Adapun nilai-nilai budaya adalah ketika berlangsung penabuhan gamelan Kyai Guntur Madu dan Kyai Naga Wilaga yaitu pada waktu pembukaan, di tangan kanan kaum perempuan tua sudah tergenggam racikan kinang yaitu daun Sirih, Jambe, tembakau, dan kapur sirih, mereka ingin mendapatkan tempat dekat masjid untuk menanti saat-saat pertama kali bunyi gamelan ditabuh. Karena yang hadir didominasi perempuan tua, karena mereka meyakini kalau makan kinang mereka akan awet muda. Nilai-nilai yang terkandung dalam gerebegan gunungan Sekaten (Gerebeg Mulud) yang berisikan makanan secara filosofis gunungan tersebut melambangkan kemakmuran dan kesuburan, penggotongannya merupakan simbol kemurahan hati raja kepada rakyatnya. Dan setelah itu dilakukan do'a dan kemudian diperebutkan masyarakat untuk dinikmati. Simbol sinkretisme politik Jawa-Islam tampak menyolok pada gelar raja-raja Jawa Islam seperti gelar Sultan, kalifahtullah sayyidin panatagama, tetunggul khalifatul Mu'minin, susuhunan, dan sebagainya. Simbol sinkretisme politik Islam-Jawa juga terdapat pada raja-raja Yogyakarta yang dipegang Sri sultan Hamengkubuwono, yaitu dengan tetap melaksanakan seluruh ajaran Islam dan tidak meninggalkan budaya, ini adalah bentuk dari pengamalan dari tradisi dan kepercayaan yang terus dilakukan terus-menerus dan berulang-ulang.

Dampak pelaksanaan Sekatenan pasca Modernisasi adalah bergesernya nilai-nilai kerakyatan karena perayaan Sekatenan untuk tahun-tahun sekarang ini lebih menonjolkan kepentingan 
bisnis. Di sisi lain nilai-nilai Islam sebagai Syiar Sekatenan yaitu seharusnya dijadikan pilar terdepan mengalami pergeseran nilai sehingga nilai-nilai relegius yang terkandung dalam perayaan sekaten dijadikan aspek kedua setelah aspek bisnis yang dijadikan prioritas utama adalah tampilan Jogja Expo Sekaten (JES). Perayaan Sekaten tahun ini terkesan eksklusif untuk mereka yang memiliki modal besar, karena bagi pengusaha kecil arena tersebut tidak tepat untuk dijadikan pasar bisnis.

\section{DAFTAR PUSTAKA}

Fatah, R. A. (2005). Rekontruksi Pesantren Masa Depan. Jakarta: PT. Listafariska Putra.

Fattah, A. (2010). Asal Mula Uwa Ajengan Datang Ke Manonjaya. Bandung: CV. Wahana Iptek Bandung.

Fazari BA, M. (1996). Ikhlas Mengabdi, Biografi Uwa Ajengan Manonjaya. Manonjaya: YAMIDA.

Haedari, A. (2004). Panorama Pesantren Dalam Cakrawala Modern. Jakarta: Diva Pustaka.

Huda, R. F. (2010). Kurikulum Pesantren Miftahul Huda. Tasikmalaya: Institut Assofa Miftahul Huda. Madjid, N. (1997). Bilik-bilik Pesantren, sebuah Potret Perjalanan. Jakarta: Paramadina.

MM, M. (2006). Model-model Pembelajaran di Pesantren. Tanggerang: Media Nusantara.

Moleong, L. J. (2011). Metodologi Penelitian Kualitatif, cetakan XXIX. Bandung: PT. Remaja, Rosdakarya.

Rahardjo, M. (2010). Triangulasi dalam penelitian kualitatif.

Raharjo, M. D. (1985). Pergulatan Dunia Pesantren Dari Bawah. Jakarta: P3M.

Sugiyono. (2013). Metode Penelitian Pendidikan Pendekatan Kauntitatif, kualitatif dan R\&D. Bandung: Alfabeta. 